\title{
Pricing in electronic markets and networks
}

\author{
Martin Spann • Andreas Herrmann • David Sprott
}

Published online: 29 April 2010

(C) Institute of Information Management, University of St. Gallen 2010

\section{Introduction}

Electronic media have tremendously changed the opportunities and challenges associated with making pricing decisions. The interactive nature of information and communication technology has encouraged the use of interactive pricing mechanisms whereby the price is not solely determined by the seller, but rather developed through the interaction between sellers and buyers (Kannan and Kopalle 2001). Such interactive pricing mechanisms are now frequently used in B2B transactions, such as in procurement auctions (Jap 2003), the selling of advertisements in search engines via the generalized second-price auction (Edelman et al. 2007), or in B2C and C2C transactions, such as the ones seen on eBay (Bajari and Hortaçsu 2003).

Electronic markets increase price transparency and thereby limit seller's ability to price discriminate (Bakos 1997). For example, shopbots allow consumers to easily

\section{Spann $(\square)$}

Munich School of Management, Ludwig-Maximilians-University, Geschwister-Scholl-Platz 1,

80539 München, Germany

e-mail: spann@spann.de

\section{A. Herrmann}

University of St. Gallen,

St. Gallen, Switzerland

e-mail: andreas.herrmann@unisg.ch

\section{Sprott}

Washington State University,

Pullman, WA, USA

e-mail: dsprott@wsu.edu compare prices from different retailers and to discuss and exchange such price information with other consumers in shopping communities or via social networks (Brynjolfsson and Smith 2000; Hinz and Spann 2008). While such information sharing is likely to improve consumer decision making, having this much pricing information may overload consumers' ability to adequately process the information and make proper use of it in their decision making (Spann and Tellis 2006).

The goal of this section was to increase our understanding of pricing phenomenon in electronic markets and networks. The call for papers generated a total of 11 submissions, which went through a double-blind review process. Of these submissions, five papers were positively evaluated by the reviewers and were eventually accepted for this section.

\section{Contributions}

The five contributions in this section are all empirical in nature and focus on various market participants in auctions (including, intermediaries, buyers and sellers), name-yourown-price auctions and recommender systems.

Duan studies the impact of intermediaries in electronic markets using data from eBay auctions. She finds that the presence of brokers increases the number of successful trades, as well as auction prices. In addition, brokers help build trust by engaging in transactions with risk-averse buyers and sellers who otherwise would not participate in the market.

Bugbee, Hayne, and Wang explore bidding behavior on eBay from a functional viewpoint of the specific bidding 
path. Analyzing bidding data from two product categories (using a unique cluster analysis procedure), the authors identify two different clusters of bidding behavior across both items.

Loebbecke, Powell, and Weiss focus on sellers in online auctions in their empirical study. Based on a large online survey of private sellers, they find that repeated use of online auctions is driven by performance and effort expectations as well as by the facilitating conditions provided by auction sites.

Wang, Hao and Hu examine the effects of information provision by a seller on bidding behavior in name-yourown-price auctions. In a laboratory experiment, they demonstrate that sellers may increase their revenue by providing partial information about the secret reserve price.

Finally, Backhaus et al. develop and test a collaborative filtering recommender system for value-added services which is based on an adapted conjoint analysis. Their recommender system enables individualized recommendations and dynamic pricing of value-added services through willingness-to-pay data.

\section{References}

Bajari, P., \& Hortaçsu, A. (2003). The winner's curse, reserve prices, and endogenous entry: empirical insights from eBay auctions. RAND Journal of Economics, 34(2), 329-355.

Bakos, J. Y. (1997). Reducing buyer search costs: implications for electronic marketplaces. Management Science, 43(12), 16761692.

Brynjolfsson, E., \& Smith, M. D. (2000). Frictionless commerce? A comparison of internet and conventional retailers. Management Science, 46(4), 563-585.

Edelman, B., Ostrovsky, M., \& Schwarz, M. (2007). Internet advertising and the generalized second-price auction: selling billions of dollars worth of keywords. American Economic Review, 97(1), 242-259.

Hinz, O., \& Spann, M. (2008). The impact of information diffusion on bidding behavior in secret reserve price auctions. Information Systems Research, 19(3), 351-368.

Jap, S. D. (2003). An exploratory study of the introduction of online reverse auctions. Journal of Marketing, 67(3), 96-107.

Kannan, P. K., \& Kopalle, P. K. (2001). Dynamic pricing on the internet: importance and implications for consumer behavior. International Journal of Electronic Commerce, 5(3), 63-83.

Spann, M., \& Tellis, G. J. (2006). Does the internet promote better consumer decisions? The case of name-your-own-price auctions. Journal of Marketing, 70(1), 65-78. 